\title{
Practices and perceptions regarding pain and pain management during routine childhood immunizations: Findings from a focus-group study with nurses working at Toronto Public Health, Ontario
}

\author{
Andrew Kikuta $\mathrm{BSc}^{1}$, Fauzia Gardezi $\mathrm{MA}^{2}$, Vinita Dubey $\mathrm{MD}^{3}$, Anna Taddio $\mathrm{PhD}^{1,4}$
}

A Kikuta, F Gardezi, V Dubey, A Taddio. Practices and perceptions regarding pain and pain management during routine childhood immunizations: Findings from a focus-group study with nurses working at Toronto Public Health, Ontario. Can J Infect Dis Med Microbiol 2011;22(2):43-48.

INTRODUCTION: Despite the availability of a variety of evidencebased interventions, it has previously been reported that the majority of infants and children undergo vaccine injections without the benefit of analgesia. Nurses in public health administer a substantial number of injections; however, their attitudes and practices surrounding acute pain during vaccine injections have not been previously explored.

METHODS: A focus-group interview was conducted in Toronto, Ontario, with 10 nurses who immunize children. Participants reported their perceptions and practices with regard to vaccine injection pain and pain management.

RESULTS: Three key themes emerged: environmental and process factors, perceptions regarding the effectiveness of different analgesic interventions, and perceptions regarding pain and fear. Participants reported a lack of control over their environment, resulting in fear and discomfort for children. They recommended increased support from external partners such as school teachers and administrators. Participants reported that pharmacological interventions, such as topical local anesthetics, were not used; however, psychological and physical interventions were commonly used. Nurses questioned the effectiveness of topical anesthetics, and indicated that more education was required regarding effective analgesic interventions. Needle pain was reported to be the most prominent concern for children undergoing vaccine injections, and children were described as being fearful. DISCUSSION: Nurses reported vaccination setting, analgesic effectiveness and relative importance given to pain as important factors for pain and pain management during vaccine injections. Future studies should explore whether additional perspectives are present in vaccinators in other geographical regions. The effectiveness of educational resources and pain management programs aimed at improving current practices should be investigated.

Key Words: Immunization; Infants/children nurses; Pain management
Les pratiques et les perceptions relatives à la douleur et à la prise en charge de la douleur pendant la vaccination systématique des enfants : les découvertes d'une étude auprès d'un groupe de travail d'infirmières en santé publique de Toronto, en Ontario

\begin{abstract}
INTRODUCTION : Malgré l'accessibilité à diverses interventions probantes, on a déjà rendu compte que la majorité des nourrissons et des enfants subissent des injections de vaccins sans analgésie. Les infirmières en santé publique administrent un nombre important d'injections. Cependant, on n'a pas encore exploré leurs attitudes et leurs pratiques entourant la douleur aiguë pendant les injections de vaccin.

MÉTHODOLOGIE : Un groupe de travail de dix infirmières qui vaccinent des enfants s'est réuni à Toronto, en Ontario. Les participantes ont exposé leurs perceptions et leurs pratiques à l'égard de la douleur causée par l'injection de vaccins et la prise en charge de la douleur.

RÉSULTATS : Trois grands thèmes ont émergé : les facteurs environnementaux et méthodologiques, les perceptions au sujet de l'efficacité de diverses interventions analgésiques et les perceptions relatives à la douleur et à la peur. Les participantes ont déclaré ne pas contrôler leur environnement, ce qui entraîne de la peur et de l'inconfort de la part des enfants. Elles ont recommandé un appui accru de la part de partenaires externes comme les enseignants et les administrateurs. Elles ont indiqué que les interventions pharmacologiques, telles que les anesthésiques topiques locaux, n'étaient pas utilisées. Cependant, les interventions psychologiques et physiques étaient courantes. Les infirmières remettaient en question l'efficacité des anesthésiques topiques et indiquaient la nécessité d'obtenir plus d'information à ce sujet. Elles constataient que la douleur causée par une aiguille était la principale inquiétude des enfants qui devaient recevoir des injections de vaccins, et les enfants étaient décrits comme craintifs.

EXPOSÉ : Les infirmières ont déclaré le lieu des vaccins, l'efficacité des analgésiques et l'importance relative accordée à la douleur comme facteurs importants de la douleur et de la prise en charge de la douleur pendant les injections de vaccins. De futures études devraient examiner si des perspectives supplémentaires s'offrent aux vaccinateurs d'autres régions géographiques. Il faudrait faire des recherches sur l'efficacité des ressources de formation et des programmes de prise en charge de la douleur pour améliorer les pratiques actuelles.
\end{abstract}

of needles, anxiety and hypersensitivity, at future medical procedures (2-4). Despite these data, children infrequently receive analgesics (5). To date, no study has investigated the perspectives of nurses (who work in public health) regarding pain and pain management during routine childhood immunization. Therefore, we conducted a pilot study to determine the practices and perceptions of nurses working in public health who perform vaccine injections in children.

${ }^{1}$ Graduate Department of Pharmaceutical Sciences, Leslie Dan Faculty of Pharmacy, University of Toronto, Toronto; ${ }^{2}$ Department of Sociology and Anthropology, Carleton University, Ottawa; ${ }^{3}$ Toronto Public Health; ${ }^{4}$ Child Health Evaluative Sciences, The Hospital for Sick Children, Toronto, Ontario

Correspondence: Dr Anna Taddio, Leslie Dan Faculty of Pharmacy, University of Toronto, 144 College Street, Toronto, Ontario M5S 3M2. Telephone 416-978-8822, fax 416-978-1833, e-mail anna.taddio@utoronto.ca 
TABLE 1

\begin{tabular}{lcllc}
$\begin{array}{l}\text { Characteristics of participants } \\
\text { Participant }\end{array}$ & $\begin{array}{c}\text { Immunizations } \\
\text { number }\end{array}$ & & Age range of children \\
per week & Practice setting & $\begin{array}{c}\text { Years in practice } \\
\text { setting }\end{array}$ \\
\hline 1 & $150-200$ & Schools, public health clinics, shelters, community centres & All ages & 2 \\
2 & $60-80$ & Schools, public health clinics & 4 and older & 0.25 \\
3 & $100-150$ & Schools, public health clinics, shelters, malls & All ages & 2 \\
4 & 100 & Schools, public health clinics, shelters, community centres & All ages & 17 \\
5 & 100 & Schools, public health clinics & All ages & 9 \\
6 & 100 & Schools, public health clinics, shelters, community centres & All ages & 4 \\
7 & 200 & Schools, public health clinics & All ages & 1 \\
8 & $100-150$ & Schools, public health clinics, shelters, community centres & All ages & 9 \\
9 & $100-150$ & Schools, public health clinics, shelters, community centres & All ages & 11 \\
10 & Not available & Not available & Not available & - \\
\hline
\end{tabular}

\section{METHODS}

Nurses from a public health unit in Toronto, Ontario (Toronto Public Health [TPH]) were invited to participate in a focus-group interview to discuss their views on pain during childhood immunization. The study was conducted at the North York Civic Centre, Toronto, during regular office hours on March 19, 2009. Nurses were informed of the study ahead of time through an announcement. Altogether, 10 registered practicing nurses participated (Table 1). Based on a previous study (6) by the same investigative team and a literature review, a semistructured guide was developed to conduct the interview. The focus group was moderated by one of the authors (FG) and lasted 90 min, during which time participants were asked to describe their practices and perceptions regarding pain and pain management during routine childhood immunization, and to describe barriers to and facilitators of immunization pain management. Table 2 summarizes the interviewer guide. The session was digitally recorded and subsequently transcribed. The focus-group transcription was analyzed using directed and summative qualitative content analysis methods (7). Existing research regarding pharmacological and nonpharmacological methods of treatment were used as a basis for formulating the focus-group questions to direct the summative search for nurse responses. New topics outside of the existing research framework were identified and analyzed independently. The main study findings were presented to participants to determine whether they matched participants' experiences. The present study was reviewed and approved by the research ethics board of The Hospital for Sick Children (Toronto), and participants provided informed consent.

\section{Characteristics of participants}

\section{RESULTS}

Participants reported performing immunization injections in children in two primary practice settings: schools and immunization clinics. Nurses in the school setting reported vaccinating grade 7 students against hepatitis $\mathrm{B}$ and meningococcus, grade 8 female students against human papilloma virus, and high school or elementary school students in occasional targeted campaigns in response to public health issues. In the community clinic setting, nurses reported vaccinating children in three distinct clinic types: influenza clinics, community clinics and homeless shelter clinics. The first two clinics took place in settings such as shopping malls or community centres. Influenza clinics were open to children of all ages, including preschool-age children, while community clinics generally immunized school-age children (four to 18 years of age). Vaccinations conducted in homeless shelter clinics occassionally involved adolescents who were between 16 and 18 years of age.

\section{Pain management practices and beliefs}

Three key themes emerged: perceptions regarding environmental and process factors; practices and perceptions regarding the effectiveness of different analgesic interventions; and perceptions regarding pain and fear (Figure 1).
Perceptions regarding environmental and process factors: The nurses all expressed that they had very little control over their physical environment, and that this lack of control led to an environment that promoted anxiety in children. A major topic of discussion was how children's expectations were shaped by one another and by the 'culture' or 'atmosphere' of the school. The participants believed that for some children, watching another child or a parent receiving an immunization was helpful. However, children in schools waiting in line-ups or waiting in a small community clinic could be negatively affected by the presence of a frightened child or poor behaviour on the part of teachers or nurses.

I think you know when you are in a gymnasium or wherever it is that you are dosing - you know and as soon as that one upset child comes, the rest are watching what's happening and then they all start as a chain reaction.

Some teachers, they think it's a joke, like you know, 'the needle this big, give him or her the biggest needle you have'... and it just gets worse.

Participants reported that the school staff influences student behaviour, and lack of control over the students makes it difficult for them to relax.

In the school, the principal assigns (the teachers) to come and help us, you know, just to have a teacher present in our clinic. And unfortunately most teachers don't really want to be there, so they may be there physically but doing their own thing. But they're really not helping us.

Desirable aspects of the physical environment mentioned by participants included a private room (devoid of crowding and high levels of noise), comfortable chairs (conducive to a more relaxed posture) and good ventilation (to prevent overheating and fainting). They believed that, particularly in schools, teachers and principals could provide much of the support needed to develop an optimal immunization environment. Participants believed that schools could help by understanding the space and time requirements for the immunizations, by ensuring that teachers assist the nurses, and by educating and reminding children and parents of the reason for immunization and the exact day of the clinic ahead of the clinic day.

Sometimes kids don't even know that they are having a needle that day. So some schools are good, organized and announce to the parents that this day is the needle day so they are prepared...But some schools, they don't even remember when we are coming in.

I think with the school sometimes they think 'well the photographer was in here'... but we are running a clinic, we're not doing the way the photographer does. We need time, we need space.

One nurse commented that the environment affected immunizers as well: 
TABLE 2

\section{Focus group topic guide}

1. What challenges do you face during a standard immunization clinic?

a. Can you give me an example of a good immunization experience?

b. Can you give me an example of a bad immunication experience?

2. Do you think that children need pain management during standard immunizations?

3. Instructions to moderator: For the analgesic interventions described below, record the following information:

1. Current practices

2. Attitudes/beliefs

3. Barriers and facilitators to implementation

Analgesic interventions:

1. Pharmacological interventions: eg, topical local anesthetics, sweetening solutions, breastfeeding, vapocoolants, oral analgesics (acetaminophen, ibuprofen)

2. Psychological interventions: eg, cognitive or behavioural or combined cognitive-behavioural (eg, nurse-led, parent-led or child-led distraction, other)

3. Physical interventions: eg, injection speed, aspiration, position of infant/ child, order of injection, massage/pressure, temperature of vaccine, ice, surrounding/environment

Probes will be used to elicit detail (eg, specific considerations for children of different ages, temperaments, past experience for various interventions)

The atmosphere in a lineup, like if there's a feeling of things being out of control, the staff, us, nurses, the (vaccinators) actually get a little agitated as well and that will affect how we are dealing with the child sitting in the chair, and your having to yell, the noise level (voices overlap) up to here, and you've got this poor child you're ready to dose but you're having to yell to ask questions because of what is going on out there, you might be a little more, how do I want to say it? A little bit more abrupt with that child or distracted.

The nurses believed that a 'familiar face', such as a friend, teacher or parental presence was helpful:

At least they have somebody that they are more familiar with and can rely on and hopefully the parent can help us to support the child.

Nurses reported, however, that teachers and parents occasionally exhibited unhelpful behaviour, thus, heightening fear: teachers joking about the length of the needle, a tough love approach from parents, and 'coddling' by parents or teachers before the immunization. It was generally believed that teachers and parents who were 'in control' or maintained a calm, orderly environment in the line-ups were most helpful.

Practices and perceptions regarding the effectiveness of different analgesic interventions: Nurses reported commonly using nonpharmacological pain management interventions to manage pain during vaccine injections including psychological and physical interventions. Pharmacological interventions were rarely used. They described obtaining information about pain management techniques through informal processes, primarily colleagues, and through experience and talking to children. Participants reported that they had not received educational material or participated in professional development activities that involved methods of pain relief during immunization.

Pharmacological interventions: When discussing pharmacological interventions, the nurses mentioned that topical anaesthetics were seldom used, and most reported having limited direct experience with them. Nurses unanimously reported that topical anesthetics were not part of routine practice. They also reported that they were not responsible for informing parents and children about the availability or use of topical anesthetics and that they were not promoted for use.

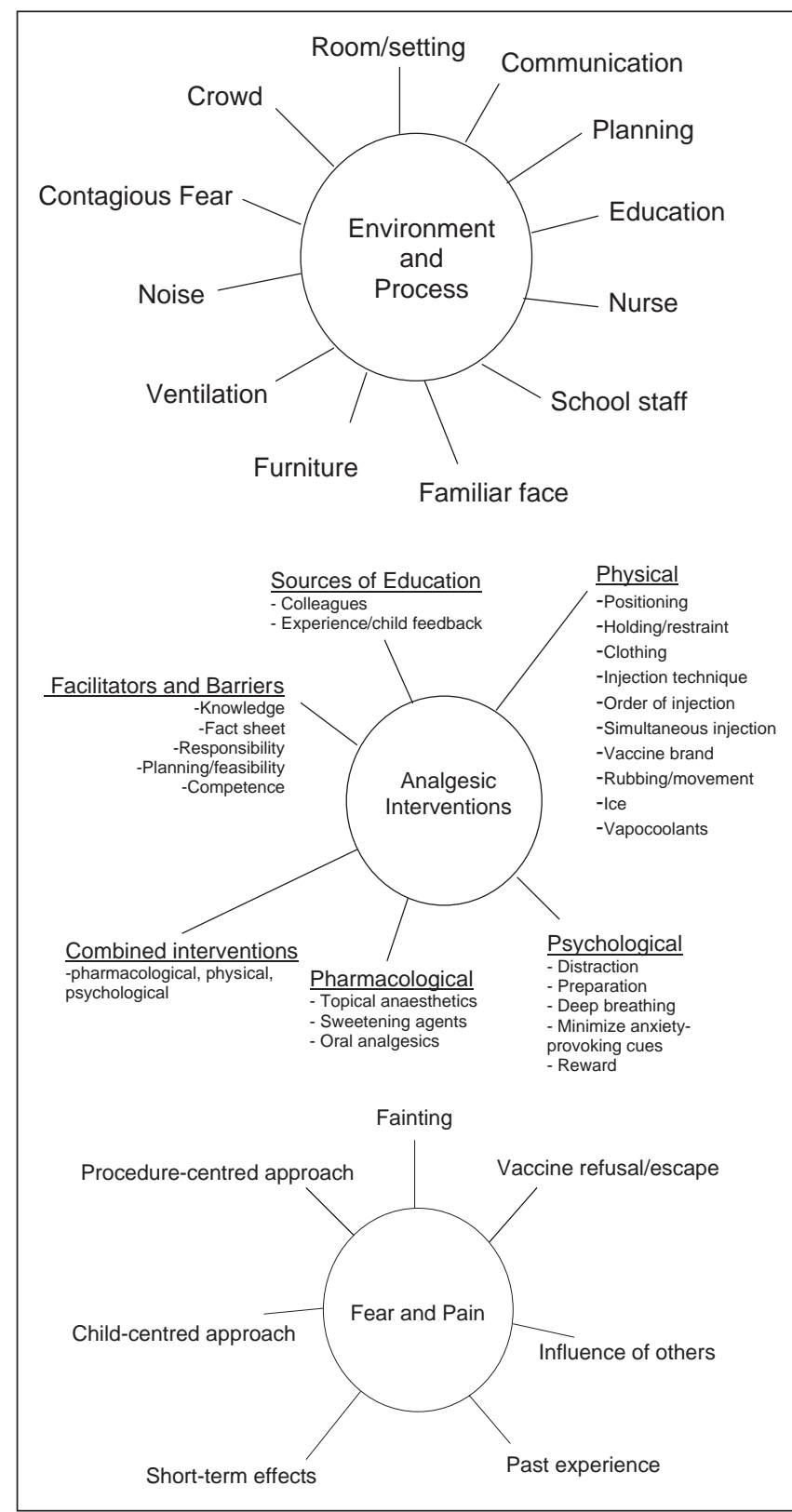

Figure 1) Three key themes that emerged from the survey

In general, we were just told it wasn't recommended in the school.

Well, no it's not encouraged. We just leave it up to the parent; it has nothing to do with ourselves or something that we would say to the parent to use or not use. It's up to each individual parent to do what they want to do.

One participant suggested that they might create false expectations, while two believed that it was not recommended for use in schools.

And what you have to do is you have to play with the student because they think it's going to work and truthfully, they don't.

Because I've had students who have come one time with that patch and the next time without the patch and you know what? It's all the same.

Nurses were unsure about the effectiveness of topical anesthetics. Some suggested they work to relieve pain via a 'placebo' or 'psychological' effect. When further questioned, they proposed that anesthetics may numb the skin, but that the pain arises primarily from vaccine infiltration, 
rather than needle puncture. Nurses further reported, however, that they did not have enough information about them.

We don't know. We don't have the knowledge; we're not up to date.

Nurses reported organizational barriers to topical local anesthetic use including responsibility for educating parents, for organizing their use and applying them appropriately, and potential inequality of access (although no nurse was able to recall any specific instance when the use of a topical anesthetic in one student generated protest from others). When asked about enablers for the use of topical anesthetics, several participants mentioned that they themselves required more knowledge about efficacy and clear guidelines with specific recommendations, as well as a fact sheet from an authoritative body (ie, the $\mathrm{TPH}$ ) for parents (so that parents would be aware of them and nurses could use the fact sheet to advocate for their use). Other pharmacological interventions, such as oral analgesics or sweetening agents (eg, sugar water), were not used by participants to manage vaccine injection pain.

Psychological interventions: Participants reported that they commonly used psychological analgesic interventions, primarily distraction. They all agreed that it was effective. Examples of psychological interventions reportedly used by participants included nonprocedural talk, toys, videos, counting, deep breathing, minimizing anxiety provoking cues (eg, sight of needles or smell of alcohol swabs), and postinjection rewards (eg, stickers, band-aids, happy face tattoos, lollipops and/or socializing with classmates).

A few participants referred to 'acknowledging' children's fears and telling them 'it's okay to be scared' or 'it's okay to cry' to be helpful. Participants noted that knowing what to expect before the procedure was an important intervention.

I also think pre-teaching before so they know what to expect, because I think for myself and for most of us, I think when we go back to do the second clinic, to do the same needle a second time, it's usually completely different. They know what to expect, so teaching and education and preparation is the big thing.

Several nurses mentioned that in the past, TPH nurses visited schools before immunization clinic days to educate and prepare children for immunization, but that these visits had been discontinued and replaced by in-school education via curriculum provided by the TPH (in 'teacher kits'). Participants reported, however, that there was no requirement for schools to provide the education to students. The specific contents of the teacher kits were not discussed.

Physical interventions: The participants believed that important physical interventions included the following: appropriate clothing (eg, T-shirts) that make the injection site accessible and do not interfere or rub against the injection site; tactile stimulation (rubbing) and moving the arm postinjection; stable position formed either by the parent holding the child or the child sitting back in a chair and relaxing their shoulders; and injection technique (such as the order of vaccine injection when multiple vaccines were being injected). Nurses reported that injecting the least painful vaccine first and simultaneous injections for multiple injections were used to mitigate pain. In addition, some vaccines were reported to cause more pain than others (specifically, human papilloma virus and meningococcus vaccines were reported to be more painful than hepatitis B virus vaccines). Participants reported having little to no experience using skin cooling interventions such as vapocoolant sprays. Ice was used postinjection in some cases.

Nurses reported that holding children too tightly could result in increased child distress.

Sometimes parents hold the kid too tight and the kid starts screaming because of the, they know something is going to happen, you know, they need to probably talk more rather than holding too much.
Finally, one nurse reported that a combination of interventions improved pain control.

But it's not only one answer at a time, it's often a combination of this and that.

Perceptions regarding pain and fear: Nurses reported that children were preoccupied with immunization pain.

Every student worr(ies) about the pain, every time they come they ask about pain.

They are going to sit there and ask 'is it gonna hurt?' It's the first question.

Nurses reported that children, parents and teachers could make other children afraid.

I had one little guy who came to a VIP clinic and the child next to him was screaming bloody murder, this poor child peed his pants... he was scared to death and peed his pants...I felt so awful.

Participants reported experiences with children fainting, refusing vaccination and running away from the nurse.

I've had (students) at different times fall flat out in a complete faint.

They tell you right off the bat, they are not going to have this needle. They will not have it.

When they run away we don't chase.

Fear of needles was viewed as a bigger problem than pain, with one participant mentioning an occasion in which mere discussion with the students resulted in fainting.

Participants reported that fear of pain was occassionally exaggerated.

Sometimes the child is not truly frightened... drama queen.

There was some divergence in approaches to dealing with anxious children. One participant described situations in which children were particularly anxious and this caused the participant to abort the procedure:

I've also seen the odd parent that will say 'smarten up, you know, suck it up, you're not a child, act your age'... And that's not effective. The child's embarrassed even more... Sometimes it gets very close to a little bit of abuse, especially in our flu clinics. It's like, but that's when I say to the parent 'let's just stop'.

Another participant reported that the procedure needed to be completed.

There are going to be children that are going to scream and there's nothing you can do, they still require that needle. The parents are relying on you to give that needle.

While participants related approaches they used to try to relax a frightened child, they also believed that these techniques were child dependent and sometimes did not mitigate fear.

Sometimes it's just acting up, but sometimes it's really fear. But you can say, 'would it help if a friend comes to stand with you or would it help if the teacher comes, sometimes that helps a lot. Different things you know or 'would you like one of the nurses to hold your hand or talk to you while I'm giving you the needle, so I think where they really are frightened, that helps.

Some nurses also reported making accommodations in the vaccination process for fearful children.

The teacher might come down with the names and tell us that 'these students are afraid.' So we choose to give an immunization before we start the clinic or after.

Nurses reported that past experiences that they don't know about may affect development of fear. They commented that most children said 'it wasn't so bad' afterward, or that children seemed to have forgotten the injection by the end of the $15 \mathrm{~min}$ 'aftercare' period. 


\section{DISCUSSION}

The present study examined the practices and perceptions of nurses regarding pain and pain management during routine childhood vaccine injections. Nurses primarily focused on environmental factors, which they believed had a powerful impact on the child's immunization experience and contributed to an overall negative experience for the child. Nurses also reported that fear was a major factor in childhood vaccine injections. Finally, they reported that they commonly used nonpharmacological analgesic interventions, but not pharmacological interventions, and that they lacked knowledge of evidencebased analgesic interventions.

Nurses indicated that addressing the environmental and process factors in school and community clinics could reduce the child's distress during the immunization procedure. The factors they believed they had no control over included room assignment, crowd control, noise levels, dissemination of fear through agitated children (ie, contagious fear), school staff assistance, ventilation, furniture, and communication, collaboration and education for school staff, children and parents. The impact of these environmental aspects on the child's immunization experience has not been well studied, and yet it is the primary issue that nurses identified for their practice. According to nurses, the ideal environment would most closely mirror the settings of a private practice, with the benefit of a private room; familiar face - either a teacher, friend or parent; and, in the case of a school setting, a teacher or principal firmly in control and supportive of the nurses' needs.

Participants reported that children were preoccupied with pain. Children were described as unprepared and fearful of vaccine injections. Nurses attempted to mitigate fear and manage pain using nonpharmacological interventions including psychological and physical methods. They reported that they did not receive formal education about the interventions they used. Instead, they learned about them from colleagues and through past experiences. They recommended that educational materials be developed so that they, and parents and children, could acquire the necessary knowledge. Furthermore, they suggested that they could use such information to advocate on behalf of children for more effective pain management practices.

Psychological interventions, such as distraction, reward and procedure preparation, were identified by nurses as being beneficial and commonly used during vaccine injections. These views and practices are consistent with the findings of a systematic review of 28 needle procedure studies (8), which concluded that psychological interventions and distraction in particular, were effective in reducing anxiety and pain, although the efficacy of these interventions were dependent on the age and psychological development of the child (8). Another review by DeMore and Cohen (9) reported that distraction is particularly effective if it directly engages the child, requires an 'overt behavioural response' and involves multiple senses. Preparation and information-based interventions, in which the child is provided information or instructions about the upcoming procedure to prepare him/her for what to expect, have also been found to reduce behavioural distress (8). Additional advantages of these interventions include ease of use and low financial burden (8), although DeMore and Cohen (9) also suggested that an educational training session on intervention techniques may be required for children and parents to optimally apply these interventions.

Nurses reported little experience with topical local anesthetics and uncertainty about their effectiveness. A recent systematic review (10) clearly demonstrated the effectiveness of topical anesthetics for reducing pain during children's immunizations. Barriers identified in the present study that prevent topical anesthetics from being used include unfamiliarity with them and their effects, and organizational aspects of their use. These results are consistent with previous research.

The present study had several limitations that warrant discussion. First, only a single focus group was conducted and all perspectives may not have been identified. Second, all participants worked in Toronto and, thus, their perspectives may be specific to that geographical region. Additional studies that include vaccinators from other disciplines are warranted, including physicians and pharmacists, as well as other stakeholders such as children and school administrators, and alternative geographical regions, to determine whether there are additional perspectives to those represented in the present sample of nurses. We are currently conducting additional qualitative interviews with clinicbased nurses and physicians. Finally, we cannot determine the realworld effectiveness of the analgesic interventions used by nurses in the present study. Readers are referred to three recent systematic reviews $(10-12)$ and an overview of immunization pain in children (13) for additional information regarding the effectiveness of specific pharmacological, physical and psychological analgesic interventions.

The present study also had many strengths. First, the focus-group design allowed for a broad range of data to be identified. The group environment allowed research participants to interact not only with the moderator, but with one another, allowing group norms and attitudes to arise. Research participants are often more forthcoming in describing their attitudes and experiences in the presence of their 'peers' and will often reflect and elaborate on their own views when they hear others voice similar or divergent views. Second, the inclusion of participants with different characteristics ensured that a wide range of perspectives and experiences were described. Third, the analysis method chosen (qualitative content analysis) did not categorize perceptions and practices in a specific theoretical perspective, but provided straightforward descriptions of the phenomena of interest. Finally, member-checking methods were used, ensuring that the study findings were interpreted according to the participants' experiences.

Pain is the primary concern of children undergoing vaccine injections, and pain management is considered to be a basic human right. Children typically develop needle fears because of negative past experiences with needles and their expectations of pain, and these fears persist into adulthood where it is estimated that upwards of $25 \%$ of adults have a fear of needles (14). Efforts to mitigate pain are expected to prevent the development of needle fears and its negative sequelae, including nonadherence to immunization schedules. Based on the present study and our previous qualitative study with parents (6), we recommend that educational materials and curricula be developed for all stakeholders involved in immunization, and that analgesic interventions be incorporated into vaccination programs across all settings so that children of all ages benefit from less pain and fear during vaccine injections. To achieve optimal pain management, a collaborative and coordinated approach among researchers, policy makers, vaccinators, school administrators and families are required, and a shift from the traditional 'procedure-centred' approach to immunization to a 'child-centred' (and hence, 'atraumatic') approach (13). Any additional time involved in the implementation of pain management interventions, including optimizing the vaccination environment, is expected to be offset by a reduction in the time required to educate and prepare children for immunization during the actual clinic days; a reduction in the time required to mitigate fear; and an increase in satisfaction with the immunization experience for all involved. Finally, we recommend further research aimed at evaluating the effectiveness and impact of routinely providing analgesic interventions.

ACKNOWLEDGEMENTS: The authors thank Ms Jess Rogers and Ms Jennifer Kiura from the Centre for Effective Practice (Toronto, Ontario), for assisting in the organization of this focus group.

\section{REFERENCES}

1. McKeown D. Childhood immunization coverage in Toronto.

In: Officer M, ed. Toronto: City of Toronto, 2009.

2. Jacobson R, Swan A, Adegbenro A, Ludington S, Wollan P, Poland G. Making vaccines more acceptable - methods to prevent and minimize pain and other common adverse events associated with vaccines. Vaccine 2001;21:17-9.

3. Weisman S, Berstein B, Schechter N. Consequences of inadequate analgesia during painful procedures in children.

Arch Pediatr Adolesc Med 1998;152:147-9. 
4. Taddio A, Shah V, Gilbert-MacLeod C, Katz J. Conditioning and hyperalgesia in newborns exposed to repeated heel lances. JAMA 2002;288:857-61.

5. Taddio A, Manley J, Potash L, Ipp M, Sgro M, Shah V. Routine immunization practices: Use of topical anesthetics and oral analgesics. Pediatrics 2007;120:e637-43.

6. Parvez E, Stinson J, Boon H, Goldman J, Shah V, Taddio A. Mothers' beliefs about analgesia during childhood immunization. Paediatr Child Health 2010;15:289-93.

7. Hsieh H-F, Shannon SE. Three approaches to qualitative content analysis. Qual Health Res 2005;15:1277-88.

8. Uman LS, Chambers CT, McGrath PJ, Kisely S. Psychological interventions for needle-related procedural pain and distress in children and adolescents. Cochrane Database Syst Rev 2006(4):CD005179.

9. DeMore M, Cohen LL. Distraction for pediatric immunization pain: A critical review. J Clin Psychol Med Settings 2005;12:281-91.

10. Shah V, Taddio A, Rieder MJ; HELPinKIDS Team.

Effectiveness and tolerability of pharmacologic and combined interventions for reducing injection pain during routine childhood immunizations: Systematic review and meta-analyses. Clin Ther 2009:31(Suppl 2):S104-51.

11. Taddio A, Ilersich AL, Ipp M, Kikuta A, Shah V; HELPinKIDS Team. Physical interventions and injection techniques for reducing injection pain during routine childhood immunizations: Systematic review of randomized controlled trials and quasi-randomized controlled trials. Clin Ther 2009;31(Suppl B):S48-76.

12. Chamber CT, Taddio A, Uman LS, McMurtry CM; HELPinKIDS Team. Psychological interventions for reducing pain and distress during childhood immunizations: A systematic review. Clin Ther 2009;31(Suppl B):S77-103.

13. Taddio A, Chambers CT, Halperin SA, et al. Inadequate pain management during childhood immunizations: The nerve of it. Clin Ther 2009;31(Suppl B):S152-67.

14. Guideline statement: Management of procedure-related pain in children and adolescents. J Paediatr Child Health 2006;42(Suppl 1):S1-29. 


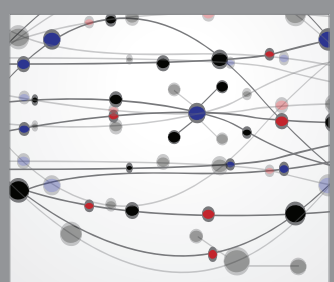

The Scientific World Journal
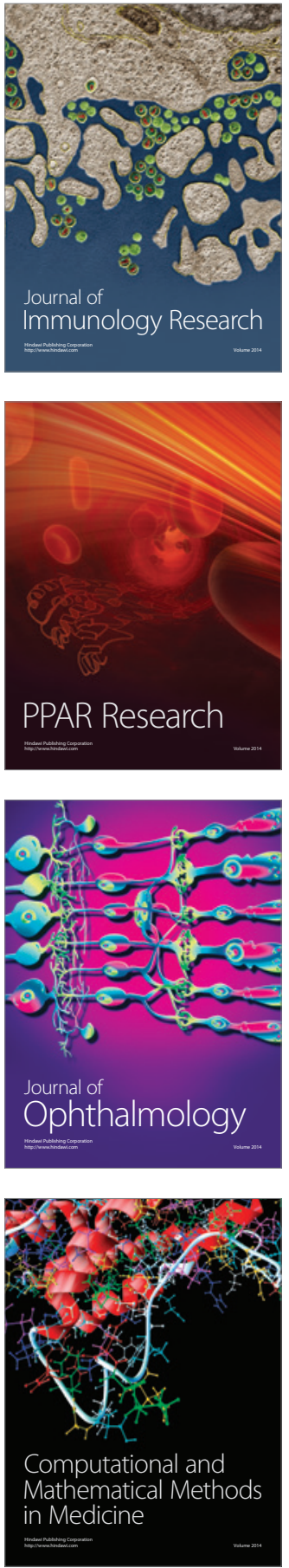

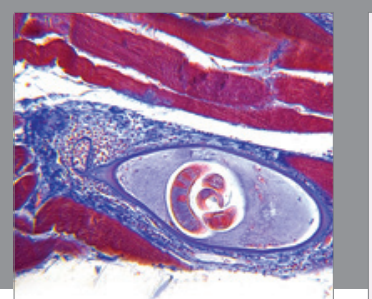

Gastroenterology Research and Practice

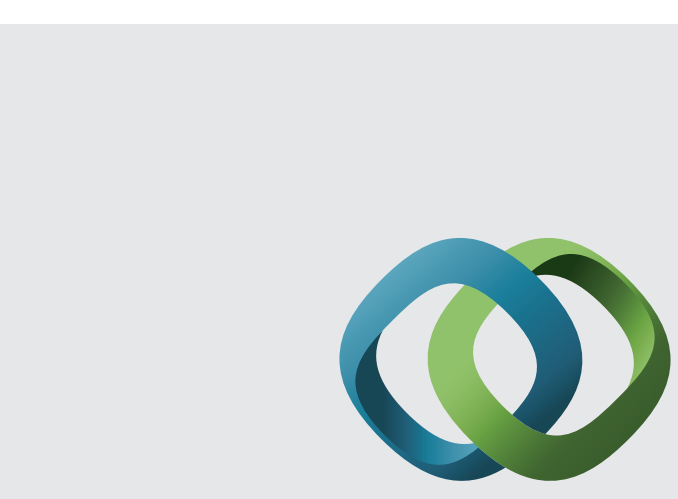

\section{Hindawi}

Submit your manuscripts at

http://www.hindawi.com
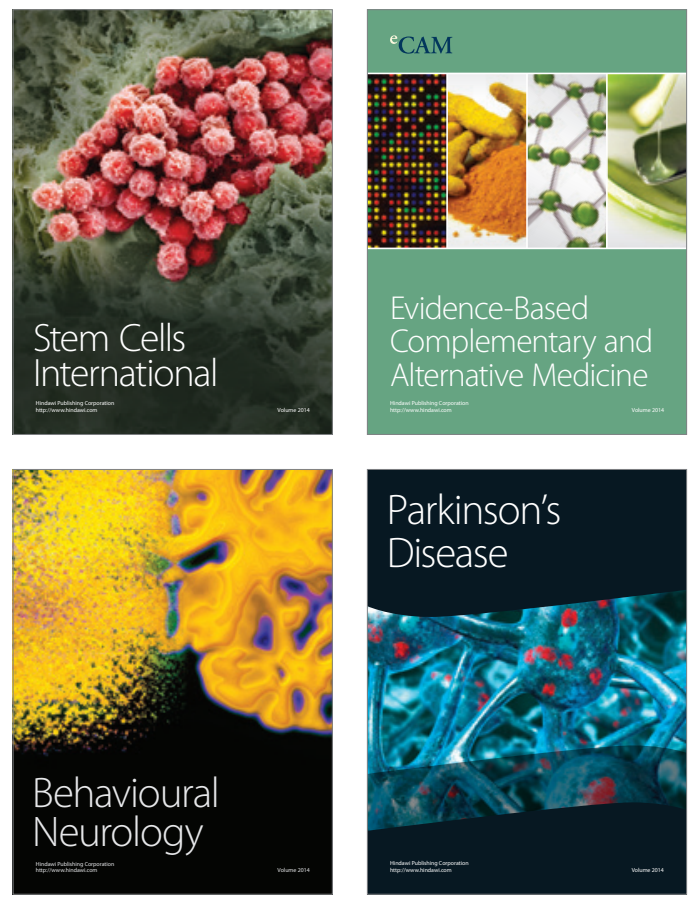
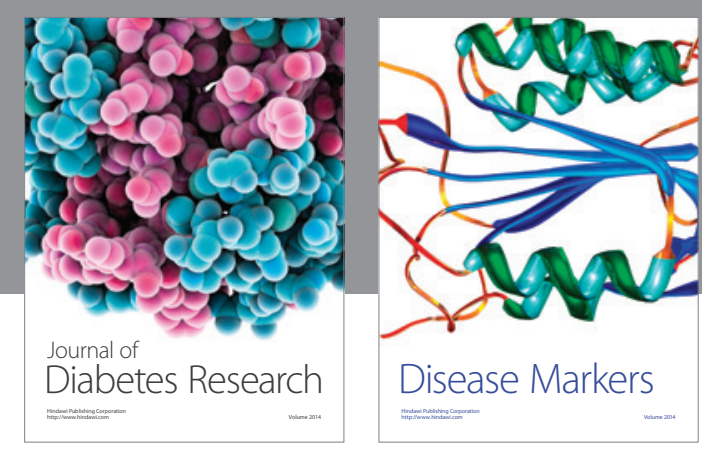

Disease Markers
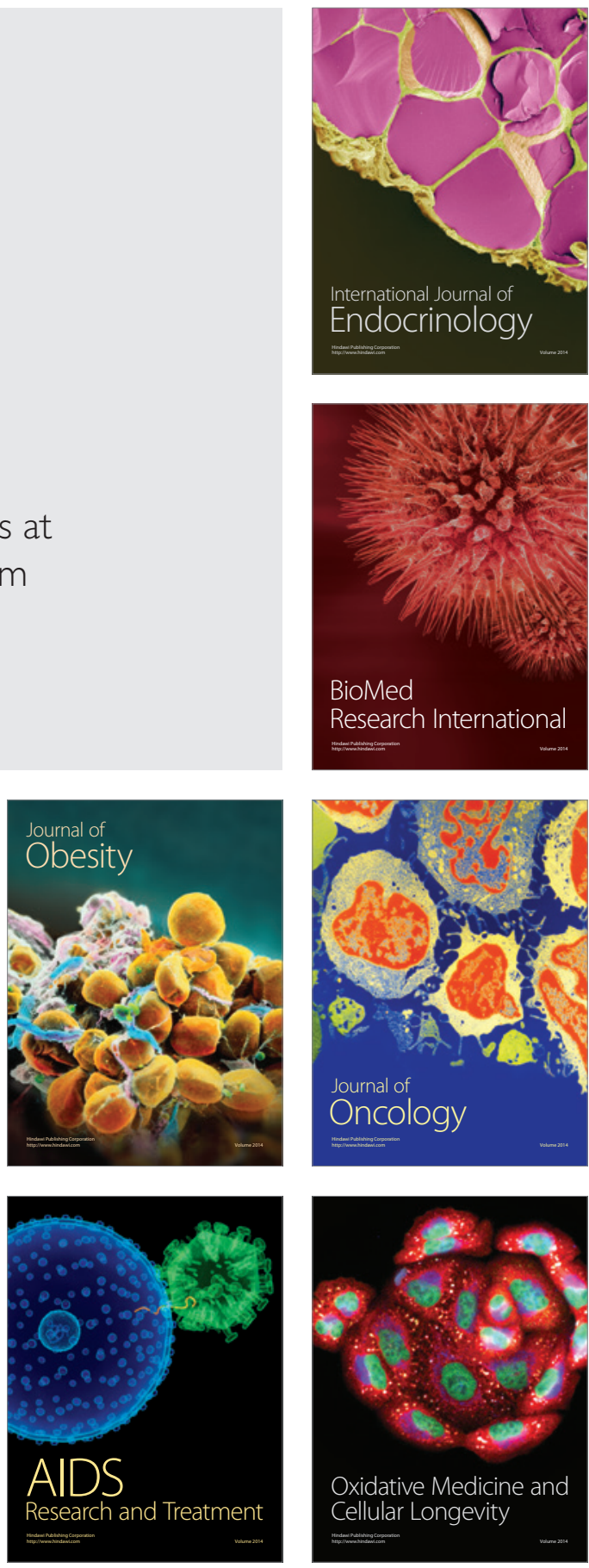